\title{
The workload of neurosurgeons: implications of the 1987 practice survey in the USA
}

\author{
Matthew Menken
}

\begin{abstract}
The number of neurosurgeons per million population is much lower in Europe than in the USA, where the point prevalence of neurosurgeons doubled between 1963-87. Results of a 1987 survey of USA neurosurgical practice show that surgery filled $25 \%$ of total time in professional activity. Of all cases treated, $64 \%$ were spinal disorders and $24 \%$ were intracranial disorders. Use of a relative value scale for neurosurgical procedures makes possible a rough and ready estimate of a neurosurgeon's weekly aggregate workload. However, the concept of a mean surgical workload must be examined within the context of the known variation of case $\mathrm{mix}$ and volume of surgical services in different practices.
\end{abstract}

Information about the total number of doctors in a medical or surgical specialty, including their density per head of population, is of limited value in determining the role that each group of specialists fills, or should fill, in medical practice and patient care. In the case of neurology, for example, the Association of British Neurologists has recommended five neurologists per million population for optimum care, whereas the Committee on National Needs for Neurologists of the American Academy of Neurology has recommended 60 neurologists per million population (exclusive of faculty needs), even though the burden of neurological illness in the populations of the United Kingdom and United States are similar. ${ }^{12}$ Thus practice studies are of special interest and importance, as they provide the scientific information to determine the scope and content of professional activities of each group of doctors. Moreover, practice studies may show changes over time in the range and volume of tasks performed by different groups of doctors in ways that may be socially beneficial or wasteful.

The prevalence rates of neurosurgeons per unit of population are much lower in Europe generally, and the United Kingdom specifically, than in North America. In the UK, there were 112 consultant neurosurgeons in 1987, or one neurosurgeon for 500000 people, compared with an average density of about one neurosurgeon for 285000 people in Western Europe. ${ }^{3}$ As of January 1987, there were 238 neurosurgeons in Canada, or about one neurosurgeon for 108000 people. ${ }^{4}$ In the USA, there were 3625 neurosurgeons in 1987 , or one neurosurgeon for 68000 people. As there were only 1818 neurosurgeons in the USA in 1963, the point prevalence of USA neurosurgeons increased by $99.4 \%$ during this period. ${ }^{5}$

There is a 20 year history of concern among professional societies in North America and Europe about the effects of an increasing total supply of physicians and surgeons upon the workload of individual practitioners. As Jennett observed nearly a decade ago, there is a "dilution of experience that must inevitably result when there are more doctors (of any specialty) for a similar disease incidence". ${ }^{6}$ As an example of this problem, the frequently cited 1975 Study on Surgical Services for the United States (SOSSUS) demonstrated that many general surgeons were performing fewer than 50 operations each year. ${ }^{7}$

In 1971, The American Association of Neurological Surgeons (AANS) established a Neurosurgical Manpower Committee to examine these issues. Even though neurosurgeons in 1973 and 1974 worked an average of 67 hours per week, had 45 hospital patients per week, and 53 weekly office patients, this group concluded that "It would appear risky to continue the present proliferation of neurosurgeons ...". This conclusion was determined, in part, by practice data which revealed that approximately $83 \%$ of all procedures performed by neurosurgeons were considered minor (such as spinal puncture, myelography, and arteriography, among others), only $17 \%$ were considered major (such as laminectomy, discectomy, and craniotomy, among others), and that about $68 \%$ of hospital inpatient encounters involved neurological problems that did not call for the performance of any procedure. ${ }^{89}$

In 1987, AANS and the Congress of Neurological Surgeons, together with the Joint Council of State Neurosurgical Societies, sponsored the Comprehensive Neurosurgical Practice (CNP) Survey in the USA, to collect data about many aspects of neurosurgical practice in $1986 .{ }^{4}$ Because many neurosurgeons and neurologists outside of North America are unfamiliar with the results of this study, a summary and analysis of the data is presented to delineate what is being done by practising neurosurgeons. In a 1985 survey of patient encounters in neurological practice in the UK, a consensus emerged that such studies provide essential information and insight about the professional role and social space of specialist practices. ${ }^{10}$

Selected demographic features of US neurosurgeons

Although the mean 1987 point prevalence rate of USA neurosurgeons was 1 per 68000 people, the distribution of neurosurgeons, like all specialists, is uneven, with clustering in urban areas and those locations generally thought to 
have desirable demographic features. There were only 37000 people per neurosurgeon in the state of Maryland, contrasted with 236000 people per neurosurgeon in the state of South Dakota. Likewise, in the London Metropolitan Region, the number of people per neurosurgeon varied by as much as $100 \%$. $^{3}$

Of 1068 full time neurosurgeons who responded to the survey, their mean age was 48; $86 \%$ were certified by the American Board of Neurological Surgery. Eighty nine per cent provided a broad range of neurosurgical services; 64 neurosurgeons limited practice to a subspecialty, commonly disorders of the spine (23) or of infants and children (15). Other data sources reveal that, in September 1988, 39 neurosurgical residents, or $6 \cdot 2 \%$, were foreign medical graduates (FMGs), and 50 neurosurgical residents, or $7.9 \%$, were women. ${ }^{11}$ In neurology, the corresponding number of residents (percentage) were $281(21 \cdot 2)$ FMGs and $357(26 \cdot 9)$ women.

\section{Selected aspects of neurosurgical practice} Approximately $87 \%$ of US neurosurgeons are engaged in private practice, but $56 \%$ have an academic appointment. Slightly more than one third of all neurosurgeons are in solo practice. About $51 \%$ are in groups of single specialty $(43 \%)$ and multispecialty (8\%) types. Approximately one third of multispecialty groups are composed of neurologists and neurosurgeons only. Only $6 \%$ of neurosurgeons' patients are self-referred, and $83 \%$ of patients were referred by physicians, emergency room personnel, and managed health care systems. Sixty four per cent of all patients were treated for spinal disorders, and the lumbar/thoracic cases were roughly twice as prevalent as the cervical

Table 1 Neurosurgical procedures

\begin{tabular}{|c|c|c|}
\hline Procedure & Average/year & $\begin{array}{l}\text { Do not } \\
\text { perform (\%) }\end{array}$ \\
\hline $\begin{array}{l}\text { Application cranial halo } \\
\text { Posterior fusion, cervical } \\
\text { Anterior cervical disc/fusion } \\
\text { Carotid endarterectomy } \\
\text { Twist drill hole, } \\
\text { Catheter/pressure device } \\
\text { Burr Holes for haematoma } \\
\text { Craniotomy for haematoma } \\
\text { Craniotomy for meningioma } \\
\text { Craniotomy for other tumour } \\
\text { Craniectomy, cerebellar tumour } \\
\text { Craniectomy, C/P angle tumour } \\
\text { Transsphenoidal pituitary tumour } \\
\text { Craniectomy for craniostenosis } \\
\text { Craniotomy for anterior aneurysm } \\
\text { Stereotaxic Lesion, Gasserian } \\
\text { Repair dura, depressed skull Fx } \\
\text { Cranioplasty, > } 5 \text { cm. } \\
\text { Ventriculo-peritoneal shunt } \\
\text { Revision, ventricular catheter } \\
\text { Revision shunt valve/distal catheter } \\
\text { Spinal puncture } \\
\text { Myelography injection } \\
\text { Cervical Lam/decompress, } 2+\text { seg } \\
\text { Lumber Lam/decompress, } 2+\text { seg } \\
\text { Post cerv disc, unilateral } \\
\text { Lam lumbar disc, unilateral } \\
\text { Additional disc, lumbar/cervical } \\
\text { Lumb lam, extensive or re-explore } \\
\text { Ant cerv disc, 1 level, no fusion } \\
\text { Cervical laminectomy, tumour } \\
\text { Thoracic laminectomy, tumour } \\
\text { Repair myelomeningocoele, }>5 \mathrm{~cm} \text {. } \\
\text { Neurolys/transp ulnar N, elbow } \\
\text { Median N decompr, carpal tunnel }\end{array}$ & $\begin{array}{r}4 \\
4 \\
15 \\
10 \\
8 \\
\\
7 \\
9 \\
5 \\
9 \\
4 \\
3 \\
4 \\
3 \\
6 \\
4 \\
4 \\
2 \\
8 \\
5 \\
6 \\
19 \\
84 \\
6 \\
14 \\
7 \\
38 \\
9 \\
14 \\
11 \\
2 \\
3 \\
3 \\
4 \\
15\end{array}$ & $\begin{array}{r}38 \cdot 5 \\
40 \cdot 0 \\
20 \cdot 6 \\
53 \cdot 4 \\
39 \cdot 1 \\
13 \cdot 1 \\
8 \cdot 1 \\
8 \cdot 1 \\
10 \cdot 8 \\
10 \cdot 1 \\
15 \cdot 3 \\
25 \cdot 9 \\
40 \cdot 1 \\
51 \cdot 5 \\
17 \cdot 1 \\
58 \cdot 6 \\
16 \cdot 9 \\
22 \cdot 5 \\
9 \cdot 9 \\
30 \cdot 5 \\
17 \cdot 0 \\
18 \cdot 9 \\
44 \cdot 0 \\
17 \cdot 7 \\
10 \cdot 4 \\
22 \cdot 8 \\
8 \cdot 6 \\
20 \cdot 2 \\
12 \cdot 9 \\
36 \cdot 0 \\
28 \cdot 9 \\
24 \cdot 7 \\
62 \cdot 1 \\
23 \cdot 3 \\
12 \cdot 9\end{array}$ \\
\hline
\end{tabular}

spine problems. Only $24 \%$ of all cases involved an intracranial disorder. A full time practising neurosurgeon worked an average of 69 hours weekly, including 17 hours of surgery (or $25 \%$ of total time in professional activity).

Other data sources reveal that neurosurgeons, on average, generated 1988 gross revenues of US $\$ 419170$ and net income (after expenses, before taxes) of $\$ 236430,{ }^{12}$ of which the 1987 CNP Survey estimates that $75 \%$ derived from surgery, $19 \%$ from office practice, and $6 \%$ from diagnostic studies. Thus professional fees in the USA are structured so that $75 \%$ of a surgeon's income derives from surgical services that fill $25 \%$ of total time in professional activity. Average total practice expenses in 1987 were estimated at US $\$ 155$ 351 of which professional liability (malpractice) insurance was $\$ 42470$.

The workload of neurosurgeons

To examine the surgical workload of neurosurgeons, a questionnaire in the CNP Survey identified the performance rate and fees for 37 office and surgical procedures in 1986. Because of the extensive nature of this data collection process, I have narrowed and edited the results, shown in table 1 , to the 34 surgical procedures, without the financial information. These results show that many neurosurgeons filled the majority of time in professional activity caring for patients with degenerative and traumatic spinal disorders. Of those performing each procedure, neurosurgeons performed 84 myelograms, 71 lumbar laminectomies, and 47 cervical spine interventions (plus 2 operations for cervical tumours), compared with 25 intracranial procedures for benign and malignant tumours, 6 operations for anterior circulation aneurysms, and 16 burr holes and craniotomies for intracranial haematomas.

Table 1 shows that many neurosurgeons are selective in the procedures they perform. Approximately $90 \%$ of neurosurgeons perform surgery for intracranial haematoma, insert ventriculoperitonal shunts, perform lumbar laminectomies, and operate for supratentorial tumours, whereas $40-62 \%$ of neurosurgeons do not perform craniostenosis surgery, carotid endarterectomy, ' transphenoidal pituitary operations, stereotactic lesions of the Gasserian ganglion, or repair of myelomenigocoeles larger than 5 centimetres.

About $32 \%$ of all neurosurgeons who responded to the CNP Survey indicated that their surgical workload was "not busy enough", about $35 \%$ thought there are "too many neurological surgeons" in their medical service areas, whereas $19 \%$ of neurosurgeons in large metropolitan areas (more than 500000 people) responded that their office workload was "too busy". This suggests that the greatest concern among many neurosurgeons is not the total quantity of work, but rather the perceived characteristics of the operative workload.

The Burr Hole Equivalent concept

How much practice makes perfect? Although unknown, there is a consensus that frequent performance contributes to continuing com- 
Table 2 The cumulative relative values of 34 procedures

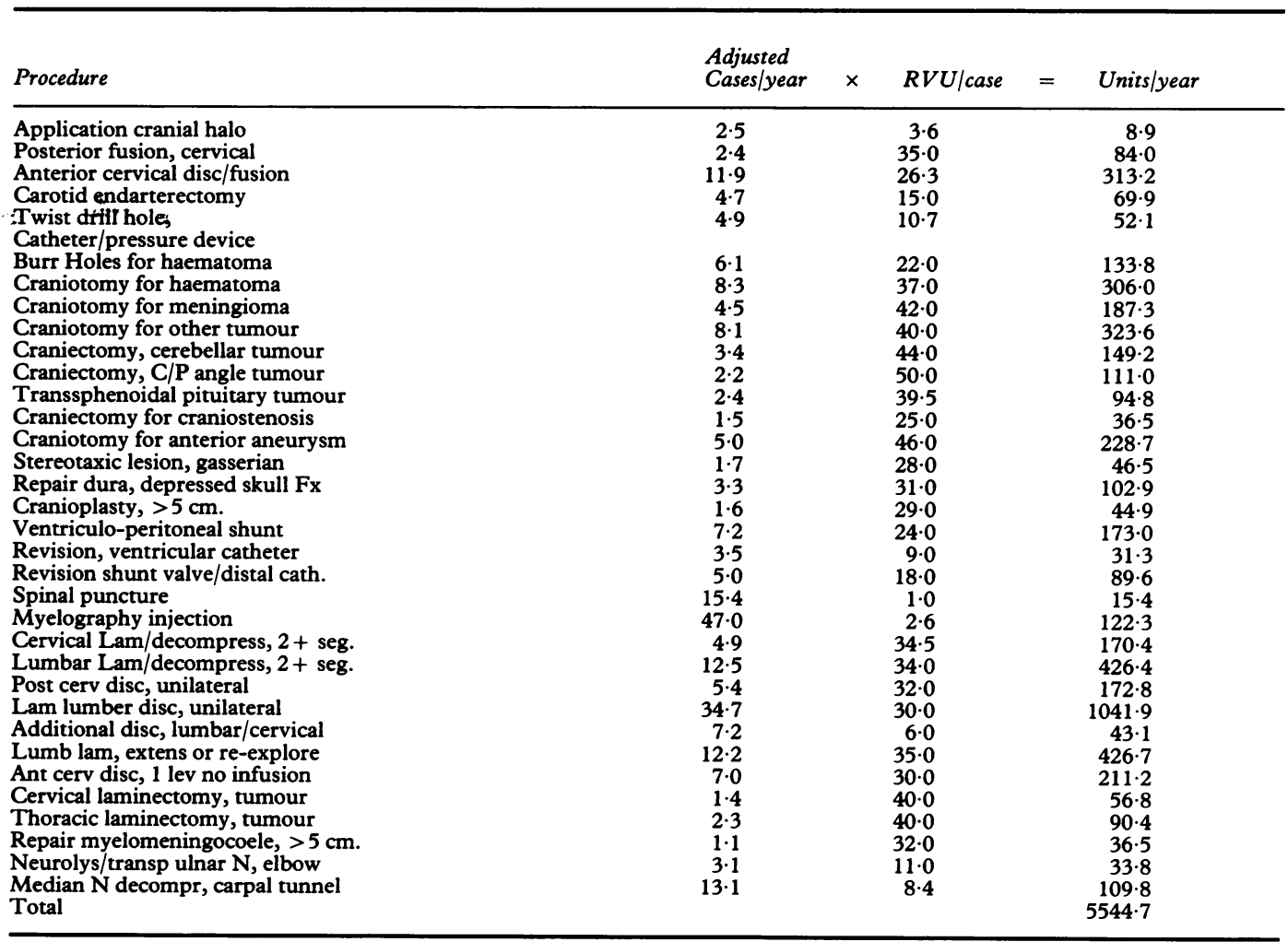

petence. ${ }^{7}$ To examine the surgical workload in general surgery in the USA nearly 20 years ago, Hughes $e t$ al developed the concept of comparing the relative value of each procedure with a herniorrhaphy (based upon comparative fees and mean operating room time), and determining the number of "hernia equivalents" of surgical work performed by each surgeon per week of practice. ${ }^{13}$ This process enables one to aggregate and compare widely disparate surgical procedures and practices.

To examine the 1987 CNP Survey results for neurosurgical procedures from this perspective, I have elected to calculate the Burr Hole Equivalent (BHE) workload of the average US neurosurgeon, employing the 1989 edition of Relative Values for Physicians (RVP). ${ }^{14}$ This relative conversion process uses five criteria to determine the relative value of each procedure: time involved; skill required; severity of illness; risk to the patient; and risk to the physician (medicolegal). For example, neurolysis and/or transposition of the ulnar nerve, elbow, is assigned 11.0 units, surgery for anterior circulation aneurysm, 46.0 units, laminectomy for excision of unilateral lumbar disc, 30.0 units, and so on.

By multiplying the mean number of times each procedure was performed annually (adjusted for the percentage of all neurosurgeons performing the procedure), by the relative value units (RVU) for that procedure, as shown in table 2 , the annual total number of relative value units is obtained for each procedure. To calculate the BHE workload of one neurosurgeon, the sum of relative value units for all 34 operative procedures (5545) was divided by the relative units assigned to one operation involving burr holes for evacuation of epidural or subdural haematoma $(22.0$ units). This process led to the conclusion that one neurosurgeon performed the equivalent of 252 burr hole procedures annually (each procedure involving one or more burr holes). Assuming 46 weeks of practice annually, the weekly workload is the equivalent of 5.48 burr hole procedures. When using this method, however, it should be emphasised that the profile of a hypothetical mean workload that emerges must be examined within the context of the known range of case mix and volume of services between and among individual surgical practices.

\section{Discussion}

More than one factor probably contributes to the highly selective workload of neurosurgeons. First, there may not always be sufficient time to do everything one would like to do. Second, the growth of neuroradiology as a subspecialty in recent years no doubt contributes to the absence of myelography among the professional activities of many neurosurgeons $(44 \%)$. Third, results suggest the frequent occurrence of an informal process of regionalisation of neurosurgical care within the catchment area of teaching centres. Many patients with carotid disease, trigeminal neuralgia, pituitary microadenomas, craniostenosis, and myelomeningocoele are referred to those surgeons with special interest and 
experience in these neurosurgical problems. Thus selectivity in practice also reflects the increasing subspecialisation of the discipline.

More than a decade ago, Drake suggested that some neurosurgeons in the USA are engaged in "what might be called the general practice of neurosurgery", with more "front line care" than "specialised neurosurgery". ${ }^{15} \mathrm{~A}$ British general practitioner has labelled such doctors less charitably as specialoids ("I thought it nicer than pseudospecialists") who provide generalist services embellished with the technology of tertiary care. ${ }^{16}$ The relevance of the case mix encountered in practice to the maintenance of knowledge and skills applies also to medical specialists, as I have previously suggested. ${ }^{17}$ For example, in the year 2000 , when each one of the 11755 neurologists in the USA will be available for the care of only 22800 people, ${ }^{18}$ a neurologist may be expected to encounter only one new patient with syringomyelia and myasthenia gravis every 10 years.

In the field of health manpower, the capacity to define the range and volume of tasks performed is a controlling influence of major importance. I would suggest that a major objective for the 1990s among the international organisations of neurologists and neurosurgeons is to develop a consensus in support of the Global Strategy for Health for All (through primary health care) of the World Health Organisation, and the educational goals of The Edinburgh Declaration of the World Federation for Medical Education. ${ }^{19} 20$ Taken together, they provide the necessary conceptual framework to identify the competencies needed by different groups of physicians and surgeons in practice, and to modify the scope and content of training programmes accordingly. ${ }^{21}$
1 Langton Hewer R, Wood VA. Neurology Services in the United Kingdom, Frenchay Hospital, Bristol, England, 1990.

2 Kurtzke JF, Bennet DR, Berg BO, Beringer GB, Goldstein $M$, Vates TS. On National Needs for Neurologists in the United States. Neurology 1986;36:383-8.

3 Maurice Williams, RS. Enough British Neurosurgeons? $\mathrm{Br}$ $J$ Neurosurg 1987;1:301-4.

4 Pevehouse BC. 1987 Comprehensive Neurosurgical Practice Study. American Association of Neurological Surgeons and Congress of Neurological Surgeons, Park Ridge, Illinois, 1988 .

5 Interim Report of the Graduate Medical Education National Advisory Committee, publication No. (HRA) 79-633. US Department of Health, Education, and Welfare, 1976: 29-33.

6 Jennett B. Efficacy, efficiency and adequacy in neurosurgery. In: Rice Edwards JM. Topical reviews in neurosurgery, vol 1. London: Wright, 1982.

7 Surgery in the United States: a summary report on the surgical services for the United States (SOSSUS). Annapolis, services for the United States (SOSSUS). Annapolis, Maryland: American College of

8 Wrenn FR, De Friese GH, Sullivan R. Neurosurgery in the Carolinas and its relation to national neurosurgical manpower requirements. Clinical Neurosurgery 1975;22: 526-65.

9 DeFriese GH, Sullivan RJ. Neurosurgical Manpower in America. Health Services Research Center, The University of North Carolina at Chapel Hill, Chapel Hill, 1976.

10 Hopkins A, Menken M, DeFriese GH. A record of patient encounters in neurological practice in the United Kingdom. J Neurol Neurosurg Psychiatry 1989;52:436-8. 11 Etzel SI, Egan RL, Shevrin MP, Rowley BD. Graduate
Medical Education in the United States. JAMA 1989;262:1029-37.

12 Owens A. Earnings: are you one of those losing ground? Medical Economics 1989;66:131-7.

13 Hughes EFX, Fuchs VR, Jacoby JE, Lewit EM. Surgical workloads in a community practice. Surgery 1972;71: 315-27.

14 Relative Values for Physicians, 3rd ed. New York: McGrawHill Information Services Company, 1989.

15 Drake CG. Neurosurgery: considerations for strength and quality. J Neurosurg 1978;49:483-501.

16 Fry J. Quoted by: Payer L. Medicine and Culture. New York: Henry Holt, 1988:104.

17 Menken M. Consequences of an Oversupply of Medical Specialists: The Case of Neurology. New Engl J Med 1983;308:1224-6.

18 Kurtze JF, Murphy FM, Smith MA. On the production of neurologists in the United States: An update. Neurology 1991;41:1-9.

19 World Health Organisation. Global Strategy for Health for All by the Year 2000. "Health For All" series 3, Geneva, WHO, 1981 .

20 World Federation for Medical Education. The Edinburgh Declaration. Medical Education 1988;22:481-2.

21 Menken M. Postgraduate Training in Neurology: Education for What? Arch Neurol 1983;40:329-32. 